\title{
Characteristics of adult women who abstain from sexual intercourse
}

\author{
Mary Nettleman, Karen S Ingersoll, Sherry Dyche Ceperich
}

\begin{abstract}
Objectives To evaluate demographic and behavioural characteristics of sexually active women compared to those who had abstained from intercourse in the past 6 months.
\end{abstract}

Methods The study participants were women of childbearing age from six sites in three states in the USA. Survey questions were asked of women who were not surgically sterile and who had not gone through menopause. The main outcome measures were correlates of sexual abstinence.

Results Of the 1801 respondents, 244 (14\%) reported abstaining from intercourse in the past 6 months. Univariate analysis revealed that abstinent women were less likely than sexually active women to have used illicit drugs [odds ratio (OR) $0.47 ; 95 \% \mathrm{Cl} 0.35-0.63$ ], to have been physically abused (OR $0.44,95 \% \mathrm{Cl} 0.31-0.64$ ), to be current smokers (OR $0.59,95 \% \mathrm{Cl} 0.45-0.78$ ), to drink above risk thresholds (OR $0.66,95 \% \mathrm{Cl} 0.49-0.90)$, to have high Mental Health Inventory-5 scores (OR 0.7, 95\% $\mathrm{Cl}$ 0.54-0.92) and to have health insurance (OR 0.74 , $95 \% \mathrm{Cl} 0.56-0.98)$. Abstinent women were more likely to be aged over 30 years (OR 1.98, 95\% Cl 1.51-2.61) and to have a high school education (OR $1.38,95 \% \mathrm{Cl}$ 1.01-1.89). Logistic regression showed that age $>30$ years, absence of illicit drug use, absence of physical abuse and lack of health insurance were independently associated with sexual abstinence.

Conclusions Prolonged sexual abstinence was not uncommon among adult women. Periodic, voluntary sexual abstinence was associated with positive health behaviours, implying that abstinence was not a random event. Future studies should address whether abstinence has a causal role in promoting healthy behaviours or whether women with a healthy lifestyle are more likely to choose abstinence.

J Fam Plann Reprod Health Care 2006; 32(1): 23-24 (Accepted 23 September 2005)

\section{Key message points}

- Sexual abstinence was associated with positive health behaviours.

- Sexually abstinent women were more likely to be older than 30 years of age.

- Sexually abstinent women were more likely to lack health insurance.

Michigan State University College of Human Medicine,

Department of Medicine, East Lansing, MI, USA

Mary Nettleman, MD, MS, Chair of Medicine

University of Virginia School of Medicine, Charlottesville, VA, USA

Karen S Ingersoll, PhD, Associate Professor

Sherry Dyche Ceperich, PhD, Assistant Professor

Correspondence to: Dr Mary D Nettleman, Michigan State University College of Human Medicine, B-425 Clinical Center, Michigan State University, East Lansing, MI 48824, USA.

Tel: +1 517432 9124. Fax: +1 4174329471

E-mail: Mary.Nettleman@ht.msu.edu

\section{Introduction}

Sexual abstinence has been discussed largely in the context of adolescent medicine, ${ }^{1-4}$ but adults also experience periods of sexual abstinence. We used survey data to identify factors associated with sexual abstinence in women aged between 18 and 44 years drawn from six diverse settings: women recently admitted to a large urban jail (Texas); residential alcohol and drug treatment facilities (Texas); a gynaecology clinic serving lowincome women (Virginia); two primary care clinics serving low-income populations (Virginia and Florida); and women responding to an urban media solicitation (Florida)

\section{Methods}

Abstinence was defined as not having vaginal intercourse with a man during the previous 6 months. Women who were in jail or a residential setting were asked about behaviours prior to entry into these settings. Questions about abstinence were only asked of women who were presumed fertile because they denied surgical sterilisation or menopause.

The survey was administered in a face-to-face interview in order to characterise women for a future interventional study. The study methodology has been described in detail previously. ${ }^{5}$ Risky drinking was defined as (1) more than seven drinks per week on average and/or (2) two or more binges in the past 6 months. ${ }^{6} \mathrm{~A}$ binge was defined as five or more drinks on one occasion. 6 The Mental Health Inventory-5 (MHI-5), a brief mental health instrument, was used as an indicator of anxiety/depression. The MHI-5 score was defined as high or low compared to the median value for the survey population. 7,8

Univariate analysis was performed using the Chisquare test in the Statistical Analysis System package (SAS v.8.0; SAS Institute Inc., Cary, NC, USA). Variables found to be significant $(p \leq 0.05)$ in the univariate analysis were included in a stepwise logistic regression. Some variables might be expected to be confounded with abstinence including sexually transmitted infection (STI), history of pregnancy and marital status. Therefore, we included these variables and the effect of setting in the logistic regression to control for their effects.

\section{Results}

There were 1801 fertile women who answered questions about sexual activity and 244 (14\%) of these had not had intercourse with a man in the past 6 months (abstainers). Twenty-four respondents had never had sexual intercourse with a man (virgins) and were included in the abstainer group. The mean age of abstainers was $32 \pm 8$ years compared to $29 \pm 7$ years for sexually active women. Age at first intercourse was $14 \pm 6$ years for abstainers compared to $16 \pm 3$ years for women who were sexually active.

The proportion of abstainers was similar across settings, with the exception of the Florida primary care clinic where $21 \%$ of women reported abstinence. In the univariate analysis, the Florida primary care setting was significantly associated with sexual abstinence $(p<0.01)$ but the other sites were not. The setting variable was included in the logistic regression. 


\section{ARTICLE}

Table 1 Results of univariate analysis

\begin{tabular}{|c|c|c|c|c|c|}
\hline \multirow[t]{2}{*}{ Characteristic } & \multicolumn{2}{|c|}{ Proportion with characteristic (\%) } & \multirow{2}{*}{$\begin{array}{l}\text { Odds ratio in abstainers } \\
\text { compared to sexually active }\end{array}$} & \multirow[t]{2}{*}{$95 \% \mathrm{CI}$} & \multirow[t]{2}{*}{$p$} \\
\hline & Abstainers & Sexually active & & & \\
\hline Age $>30$ years & 59 & 42 & 1.98 & $1.51-2.61$ & $<0.0001$ \\
\hline Illicit drugs in past 6 months & 32 & 50 & 0.47 & $0.35-0.63$ & $<0.0001$ \\
\hline Physical abuse in past year & 15 & 29 & 0.44 & $0.31-0.64$ & $<0.0001$ \\
\hline Current smoker & 35 & 48 & 0.59 & $0.45-0.78$ & 0.0002 \\
\hline Risky drinking & 27 & 36 & 0.66 & $0.49-0.90$ & 0.007 \\
\hline High MHI-5 score & 43 & 52 & 0.70 & $0.54-0.92$ & 0.01 \\
\hline Insured & 40 & 47 & 0.74 & $0.56-0.98$ & 0.03 \\
\hline High school graduate & 75 & 69 & 1.38 & $1.01-1.89$ & 0.04 \\
\hline Homeless in past year & 16 & 20 & 0.76 & $0.53-1.10$ & 0.15 \\
\hline Income $<\$ 20000$ & 71 & 67 & 1.22 & $0.91-1.65$ & 0.19 \\
\hline In jail in past year & 29 & 32 & 0.86 & $0.64-1.16$ & 0.33 \\
\hline Caucasian & 24 & 22 & 1.13 & $0.82-1.56$ & 0.44 \\
\hline Employed & 22 & 23 & 0.93 & $0.68-1.29$ & 0.68 \\
\hline
\end{tabular}

${ }^{a}$ Or equivalent certificate. MHI-5, Mental Health Inventory-5.

\section{Univariate analysis}

Compared to sexually active women, abstainers were significantly more likely to be aged over 30 years and have a high school degree or equivalent (Table 1). Abstainers were significantly less likely to have used drugs in the past 6 months, to report physical abuse in the past year, to be a current smoker, to drink alcohol above the risk level, to have MHI scores indicative of anxiety/depression or to have health insurance. The statistical significance of the associations did not change when women who had never had intercourse (virgins) were eliminated from the sample.

Women who abstained from sexual intercourse during the past 6 months were less likely ever to have been married $[p<0.0001$, odds ratio (OR) 0.43 , 95\% CI $0.32-0.56]$, less likely to have been pregnant in the past $[p<0.0001$, OR $0.50,95 \%$ CI $0.38-0.68]$ and less likely to have had a STI in the past year $[p=0.005$, OR $0.46,95 \%$ CI 0.30-0.72].

\section{Multivariate mode}

Stepwise logistic regression revealed that abstainers were significantly less likely to have used illicit drugs, to report physical abuse or to have health insurance and were more likely to be aged over 30 years than women who were sexually active (Table 2 ).

\section{Discussion}

Women who abstained from sexual intercourse differed from sexually active women in several ways. Specifically, they were older and more educated. They were less likely to engage in risk behaviours such as using illicit drugs, risky drinking or smoking. Due to the nature of the study, it was not possible to determine if abstinence had a causal role in these favourable behaviours or if the type of woman who exhibited these behaviours was simply more likely to choose abstinence.

We studied short-term abstinence, defined as reported abstinence during the past 6 months. One

Table 2 Results of logistic regression

\begin{tabular}{lllll}
\hline Characteristic & \multicolumn{2}{l}{$\begin{array}{l}\text { Odds ratio in } \\
\text { abstainers compared } \\
\text { to sexually active }\end{array}$} & $95 \%$ CI & $p$ \\
\hline Age > 30 years & 2.64 & $1.94-3.60$ & $<0.0001$ \\
Illicit drugs in past 6 months & 0.48 & $0.33-0.70$ & 0.0002 \\
Physical abuse in past year & 0.58 & $0.39-0.88$ & 0.01 \\
Insured & 0.71 & $0.52-0.97$ & 0.03 \\
\hline
\end{tabular}

limitation of our study was that sexual abstinence was self-reported and could not be verified. However, women reporting abstinence during the previous 6 months were less likely to have ever been married or pregnant or have had a STI. These findings are consistent with a sexually abstinent population. Another limitation was that the reason for sexual abstinence was not explored. Women may have been abstinent because they made an active decision to refrain from intercourse or because they wished to have intercourse but were, by chance, without a partner. ${ }^{9}$ However, chance alone would not be expected to create the significant differences found in the current analysis.

Sexual activity is a normal part of adult life. Periods of sexual abstinence also appear to be part of a normal pattern, in that they are not associated with adverse health behaviours. Further studies are needed to further explore sexual abstinence in adults.

\section{Statements on funding and competing interests}

Funding. This research was supported by the National Center on Birth Defects and Developmental Disabilities, Centers for Disease Control and Prevention (CDC) through a co-operative agreement (\#U84CCU314585). Project CHOICES is supported by a collaborative agreement research grant awarded by the Centers for Disease Control and Prevention to Virginia Commonwealth University, the University of Texas at Houston and Nova Southeastern University.

Competing interests. None identified.

References

1 Stammers $\mathrm{T}$, Ingham R. For and against: doctors should advise adolescents to abstain from sex. BMJ 2000; 321: 1520-1522.

2 Jemmott JB 3rd, Jemmott LS, Fong GT. Abstinence and safer sex HIV risk-reduction interventions for African American adolescents: a randomized controlled trial. JAMA 1998; 279: 1529-1536.

3 Khouzam HR. Promotion of sexual abstinence: reducing adolescent sexual activity and pregnancies. South Med J 1995; 88: 709-711.

4 Aten MJ, Siegel DM, Enaharo M, Auinger P. Keeping middle school students abstinent: outcomes of a primary prevention intervention. J Adolesc Health 2002; 31: 70-78.

5 Project Choices Research Group. Alcohol-exposed pregnancy: characteristics associated with risk. Am J Prev Med 2002; 23: 166-173.

6 Centers for Disease Control and Prevention. Alcohol use among women of childbearing age. MMWR Morb Mortal Wkly Rep 2002; 51: 273-276.

7 Weinstein MC, Berwick DM, Goldman PA, Murphy JM, Barsky AJ. A comparison of three psychiatric screening tests using receiver operating characteristic (ROC) analysis. Med Care 1989; 27: 593-607.

8 Tarlov AR, Ware JE, Greenfield S, Nelson EC, Perrin E, Zubkoff M. The Medical Outcomes Study: an application of methods for monitoring the results of medical care. JAMA 1989; 262: 925-930.

9 Donnelly D, Burgess E, Anderson S, Davis R, Dillard J. Involuntary celibacy: a life course analysis. J Sex Res 2001; 38: 159-169. 